\title{
Research on digital economy boosting the transformation and upgrading of traditional industries in Foshan City
}

\author{
He JIANG ${ }^{1, a}$, Yonghui CAO ${ }^{* 1, b}$ \\ ${ }^{1}$ Department of Business Administration, Guangzhou College of Technology and Business, Guangzhou, China
}

\begin{abstract}
For a large number of traditional industries, digital transformation is an all-round, multi angle and whole chain transformation process using digital technology. In recent years, Foshan has made some progress in Internet technology, industry, application and cross-border integration, and has become the only pilot city for comprehensive reform of manufacturing transformation and upgrading in China. However, for the traditional industries, the constraints of resources and energy, the increasing pressure of ecological environment, the gradual decline of demographic dividend and other factors restrict economic development to meet challenges. By deepening the application of digital technology in production, operation, management and marketing, it is an important way to realize the digital, network and intelligent development of enterprises and industries, and constantly release the amplification, superposition and multiplication effect of digital technology on economic development. It is an important way to realize the quality change, efficiency change and dynamic change of traditional industries. This is also the only way to promote high-quality economic development. In this paper, through the exploration of informatization and digitization to promote the transformation and upgrading of traditional industries in Foshan City and the realization of the path, it is of great significance for the sustainable development of high-quality economy in Foshan City.
\end{abstract}

\section{Introduction}

At present, with the advent of digital wave, the new generation of digital technology represented by big data, cloud computing and artificial intelligence is changing with each passing day, giving birth to the new economic development form of digital economy. In the past 20 years, the full development of consumer Internet has provided important opportunities for the innovation of digital technology, the growth of digital enterprises and the vigorous development of digital industry in China[1]. With the integration and application of digital technology and the deepening of China's supply side structural reform, accelerating the integration and development of digital technology and traditional industries has become a consensus. For a large number of traditional industries, digital transformation is an all-round, multi angle and whole chain transformation process using digital technology[2]. By deepening the application of digital technology in production, operation, management and marketing, it is an important way to realize the digital, network and intelligent development of enterprises and industries, and constantly release the amplification, superposition and multiplication effect of digital technology on economic development[3]. It is an important way to realize the quality change, efficiency change and dynamic change of traditional industries. This is also the only way to promote high-quality economic development.

At present, many Foshan manufacturing enterprises, under the guidance of the government, use the Internet, big data, artificial intelligence and other transformation and upgrading of traditional industries, expand high-quality supply and improve supply efficiency; the industrial Internet platform and industrial e-commerce platform dominated by enterprises are constantly emerging, helping traditional enterprises to digital transformation and cultivating new driving force of economic development[4]. Digital economy embedded in the traditional manufacturing industry has become the "golden key" for the transformation and upgrading of Foshan's manufacturing industry. The degree of innovation determines whether the manufacturing industry can continue to maintain global competitiveness without relying on cheap labor and capital investment, and whether it can realize the upgrading of global value chain.

The digital transformation of traditional industries is an important way for the high quality development of manufacturing industry in Foshan. In the process of Foshan City from "manufacturing city" to "manufacturing strong city", traditional industries are facing the constraints of resources and energy, increasing ecological environment pressure, gradually decreasing demographic dividend and other factors. The comprehensive cost continues to rise. There is great potential and market space to promote the high-quality development of manufacturing industry by upgrading traditional industries. For example, since the end of 2011, Foshan Midea Group has actively promoted digital transformation with an investment of more than 10 billion yuan to comprehensively reconstruct the system, 
implement process end-to-end and data end-to-end. The automation rate of production line is more than twice the average level of similar household appliance enterprises, and the total number of employees has decreased from 196000 to 93000 , effectively coping with the problem of rising labor costs.

The government has been deeply aware of the significance of digital transformation of manufacturing industry, and has issued many corresponding policies and initiatives to support. For example, the reports of the 19th National Congress of the Communist Party of China clearly pointed out that we should accelerate the development of advanced manufacturing industry and promote the deep integration of the Internet, big data, artificial intelligence and the real economy. Foshan followed the national policy and first introduced the "Internet plus" action plan in Foshan in Guangdong Province in 2015. Foshan city promotes Internet plus mobile computing, cloud computing, big data and Internet of things to integrate with Foshan's manufacturing industry. Yama Chi, the first national fair to launch the Internet plus theme, officially opened the "Internet + " transformation road of a manufacturing city. Foshan has also become the only pilot city of comprehensive reform of manufacturing transformation and upgrading in China. In 2017, the government work report proposed to "accelerate the growth of digital economy"; in 2019, the government work report once again mentioned the development of digital economy, but from "accelerating growth" to "strengthening digital economy", indicating that China's digital economy has entered a fast track. Therefore, the digital transformation of Foshan traditional industries is a strong support for the development of digital economy.

In short, in addition to the top-down policy promotion of the government, from the bottom-up perspective, how to realize the transformation and upgrading of Foshan's traditional industries through digitization is an urgent problem to be solved.

\section{Problems and driving factors of traditional industry transformation and upgrading in Foshan City promoted by digital economy}

\section{1 problems in the process of digital transformation of traditional industries in Foshan}

Some enterprises do not have a good understanding and lack of methodological support. Digitalization is not only a technological update, but also a comprehensive change in business philosophy, strategy, organization and operation, which requires overall planning. At present, most of the enterprises in traditional industries in Foshan have a strong desire to digitalize, but they generally lack clear strategic objectives and practical paths. They are more focused on the introduction of advanced information systems, without planning from the height of enterprise development strategy, and there is no consensus within enterprises, especially among senior managers.

The accumulation of data assets is weak and its application scope is narrow. Digital transformation is the process of enterprise data assets accumulation and application. Data assets are the important support of digital transformation. How to process and utilize data and release data is an important problem faced by enterprises. At present, most enterprises are still in the cognitive stage rather than the action stage of data application, and the industrial data chain covering the whole process, the whole industry chain and the whole life cycle has not yet been constructed; Internal data resources are scattered in various business systems, especially the underlying equipment layer and process control layer cannot be interconnected, forming a "data island"; The external data fusion degree is not high, so it is unable to recognize the distribution and update of data comprehensively in time. The supply of core digital technology and third-party services is insufficient[4]. The digital transformation of traditional industries in Foshan City faces high costs.

On the one hand, due to the lack of core digital technology supply, such as key industrial software, underlying operating systems, embedded chips, development tools and other high-end technology fields are basically monopolized by foreign countries, and related products need to rely on imports. At present, most of the solutions on the market are general solutions, which cannot meet the personalized and integrated needs of customers and industries[5]. The digital gap is obvious, and the level of industrial collaboration is low. The imbalance and insufficiency of digital development of traditional industries in Foshan City is still prominent. The digital level of the vast majority of small and medium-sized enterprises is low, and the foundation of network and intelligence is weak.

\section{2 dynamic factors of digital economy promoting transformation and upgrading of traditional industries in Foshan}

Under the background of digital economy, the transformation and upgrading of traditional industries in Foshan City is a strategic development process selected by market players based on the dynamic changes of external environment and their own factor endowment. It is influenced by many factors. The driving force of its development is mainly composed of competitive pressure, demand pull and innovations drive.

In terms of competitive pressure, Foshan's economic development largely benefits from the rapid growth of export-oriented industries, that is, a low-end connection between international market demand and domestic lowcost labor, resources, environment and other development factors. But it also objectively locked a large number of industries at the bottom of the global vertical division of labor system, forming a strong dependence on technology, market and even resources and energy. With the recent rise in labor costs and changes in the pressure of environmental protection, traditional industries are required to innovate and explore in market, technology, products, technology, management and other dimensions, so as to realize the transformation and development based on quality and efficiency. 
In terms of demand pulling and pulling, with the deep adjustment of the world economy, domestic demand has gradually become the decisive force of China's economic growth. Consumption upgrading will play a more and more important role in promoting the growth of traditional industries. The reasons are as follows: first, there is a big gap between China's per capita durable consumer goods and developed countries; second, the service-oriented consumption space of information, medical care, pension, home economics, tourism has just opened; third, the rapid promotion of urbanization will further expand the consumption space.

In terms of innovation driven, from the perspective of technological progress, the transformation and upgrading of Foshan's traditional industries is also the process of penetration, subversion and transformation of the latest scientific and technological achievements (such as information, biology, recycling) on the existing technological routes, production processes and business models. Scientific and technological innovation not only transformed the manufacturing industry, but also gave birth to the emerging industry guided by the integration of Internet and renewable energy. By promoting the integration of material products and services, it provides industrial upgrading opportunities for the global economy to develop into new industries such as the Internet, information technology and "low carbon".

\section{Path analysis and policy thinking of digital economy promoting transformation and upgrading of traditional industries in Foshan City}

\section{1 theoretical basis of digital economy promoting transformation and upgrading of traditional industries in Foshan}

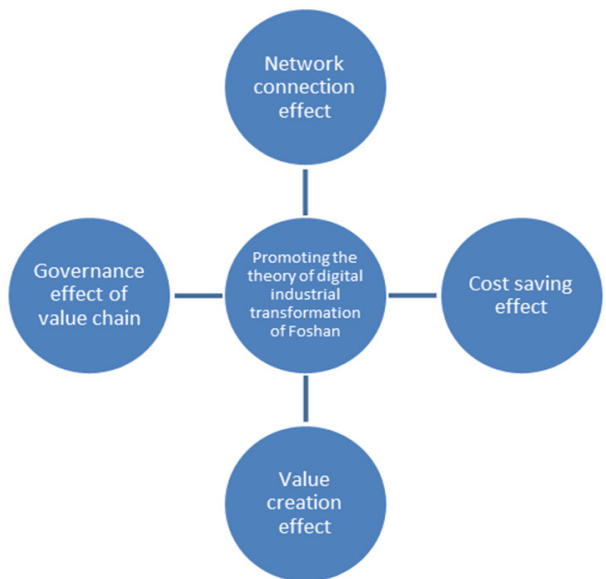

Fig1. theoretical basis of digital economy promoting transformation and upgrading of traditional industries in Foshan City

Network connection effect: digital economy helps Foshan as a traditional industry to reduce the difficulty of value chain connection. Digital economy expands digital connectivity and reduces the fixed cost of traditional industrial enterprises participating in the value chain. This is mainly due to the expansion of Internet finance financing channels and network platform to alleviate information asymmetry.

Cost saving effect: the digital economy greatly reduces transaction costs. Digital economy greatly reduces the transportation cost of information goods, and reduces the cost of information search to nearly zero, thus saving channel costs. Digital economy reduces verification costs and creates digital reputation.

Value creation effect: digital economy has become the new engine of traditional industry value creation. Digital economy brings productivity effect. First of all, there is substitution effect, and enterprises use lower cost capital (robot) to replace the low-end labor force to achieve cost saving. Secondly, it brings about factor enhancement effect. By transferring low-end repetitive work to artificial intelligence, workers can focus on higher value activities to improve efficiency.

Governance effect of value chain: platform driven model reshapes the governance structure of value chain. Digital platform reconstructs enterprise production and sales network through network effect. Digital economy makes the governance mode of value chain change from traditional consumer driven or producer driven to platform driven mode. Secondly, digital technology reconstructs supply chain governance structure through big data algorithm prediction.

\section{2 realization path of Foshan manufacturing industry transformation and upgrading promoted by digital economy}

Focus on intelligent manufacturing to promote the digital transformation of enterprises. China's traditional industries are mainly manufacturing industry, so promoting intelligent manufacturing is the main direction for enterprises to accelerate digital transformation. The automation, networking and intelligent level of traditional manufacturing mode should be comprehensively improved through "machine replacement" and intelligent transformation, and new modes and formats such as personalized customization, intelligent production, networked collaboration and service-oriented manufacturing should be promoted on this basis.

We should focus on platform enabling to promote the digital transformation of the industry. The government should guide the platform to promote the digital transformation of key industries by improving the operation mechanism, sharing data resources, selecting different action points, key points and methods according to the characteristics and operation mode of specific industries, with the leading manufacturing enterprises, industrial CT leading enterprises and Internet platform enterprises as the leading enterprises.

The government should focus on ecological construction to promote the digital transformation of the park. Industrial Park is an important carrier of industrial development, which plays an important role in guiding industrial agglomeration, promoting system reform and improving investment environment. It is the basic path to change the traditional production mode, organization mode and management mode to promote the integration 
and upgrading of various industrial platforms through the digital transformation of the park, and it is also an important support to drive the digital transformation of traditional industries.

\section{3 digital economy promotes the transformation and upgrading of traditional industries in Foshan}

We will accelerate the construction of an efficient supply system for digital technology. We should speed up the construction of a number of carriers of digital economic innovation platform, and improve the level of technological innovation, especially the original technology and basic theoretical research innovation. Efforts should be made to solve the shortage of digital innovative talents. We should clarify the ability and quality standards of digital innovative talents. On the basis of full consideration of the enterprise's demand for talents, the professional competence of digital skilled talents at all levels and the cross-border capabilities such as business operation and risk control are stipulated to promote the integration of digital professional and technical talents with various traditional industries, and improve the design of professional level of digital skilled talents based on the ability level, so as to point out the growth path for digital skilled talents.

Strengthen the policy support for the digital transformation of traditional industries. By optimizing government services and improving policy accuracy, the government can truly become the "backstage server" for digital innovation of traditional industries. It is necessary to study and formulate policy opinions and supporting policies to promote the digital development of traditional industries, integrate the policy forces of Finance and taxation, finance, talents, land and elements, and spare no effort to promote the digital transformation of traditional industries. In terms of financial and tax support, we should strengthen the overall planning of special financial funds, guide financial funds at all levels to increase investment in digital transformation of traditional industries, and strengthen support for major platforms, major projects and pilot demonstration in the field of digital economy.

Actively deploy a new generation of information infrastructure. Digital facilities represented by $5 \mathrm{G}$, artificial intelligence, industrial Internet and Internet of things are becoming an important part of new national infrastructure. Facing the industrial network demand of enterprises with low delay, high reliability and wide coverage, it is necessary to accelerate the upgrading of $5 \mathrm{~g}$ and other new generation information networks, and strengthen new information infrastructure such as industrial Internet and cloud computing.

The government should focus on optimizing the development ecology of digital economy. Creating a good ecological environment for development is the fundamental guarantee for the high-quality development of digital economy in Foshan. We should vigorously optimize the business environment of digital economy, vigorously support innovation and entrepreneurship in the field of digital economy, and develop and expand the market players of digital economy. We should actively build a platform carrier to promote resource gathering, innovation and entrepreneurship, create an institutional environment to protect property rights and support innovation, and promote the construction of a more open and collaborative industrial ecology. At the same time, by optimizing the supply of public goods from the platform, system, policy and service, the government actively creates a good development environment conducive to innovation and entrepreneurship, and builds a good ecosystem for the healthy development of Foshan digital economy.

\section{Research framework and conclusions}

In recent years, Foshan has made some progress in Internet technology, industry, application and cross-border integration, and has become the only pilot city for comprehensive reform of manufacturing transformation and upgrading in China. However, for the traditional industries, the constraints of resources and energy, the increasing pressure of ecological environment, the gradual decline of demographic dividend and other factors restrict economic development to meet challenges. With the increase of domestic and international economic instability factors, such as Sino US trade frictions, Foshan manufacturing industry can no longer rely on the low value-added links in the value chain to maintain economic and trade growth, and it is in urgent need of transformation and upgrading. In this paper, it is of great significance to explore the transformation and upgrading of Foshan's traditional industries through informatization and digitization, as well as the implementation path and policy recommendations.

Firstly, this paper analyzes the problems in the process of digital transformation and upgrading of traditional industries in Foshan; secondly, it analyzes the theoretical basis of digital transformation and upgrading of traditional industries in Foshan from four aspects: network connection effect, cost saving effect, value creation effect and value chain governance effect brought by digital economy; thirdly, this paper analyzes the driving factors of digital economy promoting the transformation and upgrading of traditional industries in Foshan City from three aspects: competitive pressure constraint and reverse force, demand traction and pull, and innovation drive. Then, from the aspects of intelligent manufacturing, platform enabling, digital ecological construction of Industrial Park, the paper explores the path of digital transformation and upgrading of traditional industries in Foshan City. Finally, from the supply of digital technology, digital innovation talents, policy support, new generation of information infrastructure and other aspects, this paper puts forward the policy thinking of promoting the digital transformation and upgrading of traditional industries in Foshan City.

\section{Acknowledgment}

This work was financially supported by Foshan social science planning project in 2020, 2020-QN11; Henan philosophy and Social Sciences Planning Project in 2019, 
2019BJJ032; The social development project of Henan provincial key R \& D and promotion project (Science and technology tackling key problems) in 2019, project number: 515. Thanks for the help.

\section{References}

1. He Xiaoyin. Development trend of digital economy and China's strategic choice [J]. Discussion on modern economy, 2013, 000 (003): 39-43.

2. Zhao Xisan. Research on the transformation and upgrading of Chinese manufacturing driven by digital economy [J]. Zhongzhou academic journal, 2017, no. 252 (12): 42-47.

3. Xiao Suyang. Research on the transformation and upgrading of "China's manufacturing industry" under the background of digital economy [J]. Guangxi quality supervision guide, 2019, 000 (006): 188-189.

4. Song Ge. Research on accelerating the transformation and upgrading of traditional manufacturing industry in the era of digital economy [J]. Industrial innovation research, 2019.

5. Li Yonghong, Zhang Shuwen. The path of transformation and upgrading of traditional industries driven by big data -- Based on the perspective of big data value chain $[\mathrm{J}]$. Science and technology management research, 2019, 039 (007): 156-162. 